INDICE CUMULATIVO DOS VOLUMES 1 A 25 (1953-1989) 


\section{ÍNDICE DE TÍTULOS}

* Abalroamento aéreo. (a. 3, n. 3, p. 146-171,dez. 1955).

* Ação rescisória e homologação de transação. (a. 19, n. 19, p. 101-116, 1978/79/80).

* Acidente de trabalho e previdência social. (a. 11, n. 11, p. 161-172. 1968).

* Ações cautelares. (a. 21, n. 21, p. 29-62, 1983/84).

* Ações de companhias e sua negociação obrigatória em pregão público. (a. 2, n. 2, p. 262-270, dez. 1954).

* Adoção. (a. 1, n. 1, p. 147-156, dez. 1953).

* A adoção e sua nova lei. (a. 6/7, n. 6/7, p. 211-220, 1958/59).

* O advogado e a justiça do trabalho: em homenagem a um senhor advogado. (a. 25, n. 25, p. 125-138, 1989).

* Ainda as diretrizes e bases da educação nacional. (a. 8, n. 8 , p. $55-80,1960$ ).

" Algo sobre a empresa. (a. 11, n. 11, p. 67-80, 1968).

* Algumas anotações sobre os crimes contra os costumes. (a. 22, n. 22, p. 224-235, 1985).

* Algumas inovações no anteprojeto de código de processo civil. (a. 13, n. 13, p. 155-166, 1970).

- Alguns aspectos da individualização da pena. (a. 6/7, n. 6/7, p. 228-237, 1958/59).

- Alguns aspectos da problemática médico-social do complexo de inferioridade. (a. 8, n. 8, p. 81-99, 1960).

- Alguns aspectos do furto neurótico. (a. 1, n. 1, p. 91-97, dez. 1953).

- Alguns aspectos políticos e sociológicos de uma revisão territorial do Brasil. (a. 11, n. 11, p. 187-202, 1968). 
- Alguns aspectos psiquiátrico-legais do suicídio. (a. 6/7, n. $6 / 7$, p. $58-62,1958 / 59$ ).

* Alguns comentários sobre a administração da justiça na União Soviética. (a. 13, n. 13, p. 11-32, 1970).

" "El amparo", el mandado de segurança y el sistema de garantias jurisdiccionales del D. Uruguayo. (a. 8, n. 8, p. 153-171, 1960).

* Anibal Bruno e a reforma penal. (a. 18, n. 18, p. 23-42, 1976/77).

- Os antecedentes da Declaração dos Direitos de 1789 e sua evolução. (a. 24, n. 24, p. 135-152. 1987/88).

- Aplicação judiciária da narco-análise. (a. 5, n. 5, p. 217-222, dez. 1957).

* Apontamentos sobre a individualização da pena. (a. 11, n. 11 , p. 173-186, 1968).

- Apontamentos sobre o crime político. (a. 14, n. 14, p. 29-44, 1971).

* Apontamentos sobre os estados de perturbação geral da consciência. A emoção e a paixão. (a. 20, n. 20, 105-132, 1981/82).

- Aspectos da culpabilidade no direito penal. (a. 10, n. 10, p. 89-106, 1964/67).

- Aspectos de la sentencia del tribunal de lo contensioso administrativo. (a. 10, n. 10, p. 23-42, 1964/67).

* Aspectos do anteprojeto de código penal. (a. 9, n. 9, p. 85-122, 1961/63).

* Aspectos do crime continuado. (a. 12, n. 12, p. 137-150, 1969).

* Aspectos gerais do direito contratual polonês. (a. 12, n. 12, p. 11-38, 1969).

* Associação comercial de São Paulo - Instituto Jurídico. (a. 14, n. 14, p. 73-106, 1971).

* A atividade administrativa do Estado. (a. 17, n. 17, p. 69-124, 1974/75). 
- Ato administrativo: conceito e elementos. (a. 22, n. 22, p. 6-121, 1985).

- Autarquias e empresas públicas. (a. 15, n. 15, p. 20-42, 1972).

* As causas da exclusão da culpabilidade do novo código penal. (a. 15, n. 15, p. 166-184, 1972).

* A centralização no Estado Federal. (a. 22, n. 22, p. 122-145, 1985).

* A ciência e a arte política. (a. 3, n. 3, p. 100-131, dez. 1955).

* A cisão de sociedades. (a. 18, n. 18, p. 91-94, 1976/77).

* Citação pelo correio. (a. 18, n. 18, p. 83-90, 1976/77).

* Classificações das ações. (a. 18, n. 18, p. 71-82, 1976/77).

* A cláusula de arbitramento compulsório de litígios, nos tratados interamericanos. (a. 2, n. 2, p. 93-121, dez. 1954).

" A "clementia principis" de nossos dias, no direito nacional. (a. $6 / 7$, n. $6 / 7$, p. 203-210, 1958/59).

* O código civil português de 1966. (a. 12, n. 12, p. 101-114, 1969).

* O código e o formalismo processual. (a. 21, n. 21, p. 13-20, 1983/84).

* Comentário à ponência do Prof. Lourival Vilanova, intitulada: "O substrato modalmente indiferente". (a. 24, n. 24 , p. 39-42, 1987/88).

* A compensação e a responsabilidade extra-contratual. (a. 13 , n. 13, p. 145-154, 1970).

* Conceito clássico e post-clássico do jus naturale e do jus gentium. (a. 1, n. 1, p. 26-47, dez. 1953).

* O conceito de direito em Hart. (a. 24, n. 24, p. 105-134, 1987/88).

* O conceito de serviço público e o direito administrativo. (a. 2, n. 2, p. 148-157, dez. 1954).

* Conceitos atuais da psicopatologia do suicídio. (a. 8, n. 8, p. 124-127, 1960). 
- Condenação do abuso do direito. (a. 12 , n. 12, p. 49-54, 1969).

* O consentimento do ofendido no direito penal. (a. 12, n. 12 , p. 257-270, 1969).

* Considerações sobre a responsabilidade civil do Estado por fatos dos seus agentes. (a. 23, n. 23, p. 105-128, 1986).

- Considerações sobre grupos de pressão. (a. 6/7, n. 6/7, p. 165-178, 1958/59).

- Considerações sobre o direito à intimidade das pessoas jurídicas. (a. 25, n. 25, p. 81-92, 1989).

* Considerações sobre o dolo. (a. 2, n. 2, p. 303-313, dez. 1954).

- Considerações sobre os direitos da personalidade na antiga Roma. (a. 24, n. 24, p. 57-74, 1987/88).

- A constituição de 1967 e o direito civil. (a. 17, n. 17, p. 53-68, 1974/75).

* Constituições brasileiras, legislação e terras devolutas. (a. 24 , n. 24, p. 153-192, 1987/88).

* O contrato de concessão de venda com exclusividade (concessão comercial). (a. 15, n. 15, p. 208-247. 1972).

* A contribuição das finanças públicas para estabilidade financeira interna e externa. (a. 4, n. 4, p. 170-233, dez. 1956).

* A contribuição das finanças públicas para estabilidade financeira interna e para o equilíbrio da balança de pagamentos. (a. 2. n. 2, p. 374-393, dez. 1954).

" Contribution de la "victimologie" aux sciences criminologiques. (a. 6/7, n. 6/7, p. 268-285, 1958/59).

- Convenção européia de direitos humanos e convenção americana de direitos humanos em comparação. (a. 23, n. 23 , p. 51-72, 1986).

* Cooperativismo e comunidade. (a. 6/7, n. 6/7, p. 188-202, 1958/59).

- Crimes omissivos. (a. 20, n. 20, p. 71-104, 1981/82). A criminologia de Clóvis Bevilacqua. (a. 8, n. 8, p. 7-21, 1960). 
- A culpabilidade no novo código. (a. 13, n. 13, p. 139-144, 1970).

* Cursos universitários - problemas do ensino médico (a. 4, n. 4, p. 298-306, dez. 1956).

* Da etimologia e definição do domínio. (a. 8, n. 8, p. 147-152, 1960).

* Da iniciativa das provas e dos poderes do juiz de direito romano e na atualidade. (a. 20, n. 20, p. 19-38, 1981/82).

* Da necessidade do divórcio. (a. 4, n. 4, p. 110-125, dez. 1956).

* Da reparação do dano causado pelo crime. (a. 13, n. 13, p. 89-104, 1970).

* Das penas principais e sua aplicação. (a. 9, n. 9, p. 63-72, 1961/63).

* Das relações entre a companhia e seus acionistas. (a. 19, n. 19 , p. $87-100,1978 / 79 / 80)$.

* Das sociedades coligadas e controladas. (a. 6/7, n. 6/7, p. 144-164, 1958/59).

* Delegação de poderes. (a. 2, n. 2, p. 287-290, dez. 1954).

* Delinqüência de menores. (a. 2, n. 2, p. 327-373, dez. 1954).

* Denunciação da lide. (a. 21, n. 21, p. 63-74, 1983/84).

* El derecho procesal y la proteccion del consumidor. (a. 21, n. 21, p. 121-128, 1983/84).

* A desapropriação por utilidade pública no direito brasileiro e os direitos de terceiros. (a. 19, n. 19, p. 40-62, 1978/79/80).

* Desnecessidade da presença do juiz ao ato de arrematação no sistema do código de processo civil. (a. 21, n. 21, p. 101-120, 1983/84).

* O destino do direito do trabalho. (a. 5, n. 5, p. 153-165, dez. 1957).

* A destruição do homem pela ganância do poder econômico. (a. 21, n. 21. p. 21-28, 1983/84). 
- A dialética da praxis na teoria egológica do direito. (a. 22 , n. 22, p. 236-249, 1985).

* Dicionário do investidor. (a. 16, n. 16, p. 9-62, 1973).

* La dinamica de la libre apreciacion de la proeba en la jurisdiccion civil. (a. 6/7, n. 6/7, p. 286-318, 1958/59).

* Direito, administração, Estado. (a. 1. n. 1, p. 64-72, dez. 1953).

* O direito administrativo no Brasil. (a. 9. n. 9, p. 53-56, 1961/63).

- O direito adquirido diante do futuro có digo civil. Sujeitos de direito. Pessoas físicas. (a. 19, n. 19, p. 63-86. 1978/ $79 / 80)$.

* O direito ao casamento e a sua dissolução entre os direitos fundamentais do indivíduo. (a. 19, n. 19, p. 213-222, 1978/ $79 / 80)$.

* Direito astronáutico: diretrizes e normas. (a. $6 / 7$, n. 6/7, p. 101-125, 1958/59).

* O direito comparado. (a. 15, n. 15, p. 261-274, 1972).

* Direito comparado e geografia jurídica. (a. 3, n. 3, p. 348-371, dez. 1955).

* $\mathrm{O}$ direito das obrigações no código civil português. (a. 12, n. 12, p. 93-100, 1969).

* Direito e amor. (a. 5, n. 5. p. 86-108, dez. 1957).

* Direito e dialética. (a. 17, n. 17, p. 145-158, 1974/75).

* Direito: ensino, pesquisa, teoria e prática. (a. 25, n. 25, p. 109-118, 1989).

* Direito natural em Roma. (a. 24, n. 24, p. 43-56, 1987/88).

* Direito natural - direito cultural. (a. 4, n. 4, p. 126-130, dez. 1956).

- O direito romano em sua evolução histórica. O passado e o presente. (a. 20, n. 20, p. 161-170, 1981/82). 
- Do aval dado por mulher casada sem o consentimento do marido. (a. 25, n. 25 , p. 183-188, 1989).

- Do conceito romano de imperium e seus desvios jurídicopolíticos. (a. 23, n. 23, p. 19-36, 1986).

- Do condomínio edilício e suas fontes. (a. 17, n. 17, p. 125-134, 1974/75).

- Do controle judicial das desapropriações por interesse público. (a. 18, n. 18, p. 51-70, 1976/77.

" Do direito ao nome. (a. 12, n. 12, p. 203-220, 1969).

* Do mandado de segurança contra o ato jurisdicional no direito brasileiro. (a. 9, n. 9, p. 11-18, 1961/63.

- Do tribunato da plebe e do conceito romano de justiça: breve considerações. (a. 23, n. 23, p. 9-18, 1986).

- Dois anos de sexologia forense no Departamento Médico Legal no Paraná. (a. 5, n. 5, p. 27-34, dez. 1957).

* Dois aspectos do tema suicídio. (a. 15, n. 15, p. 130-136, 1972).

* Dos crimes contra a economia popular. (a. 2, n. 2, p. 314-326, dez. 1954).

* Dos crimes contra a ordem tributária. (a. 22, n. 22, p. 202-209, 1985).

* Le droit comparé et l'unification du droit privé des pays latins. (a. 5, n. 5, p. 193-200, dez. 1957).

* A dupla interpretatividade do dever-ser. (a. 24, n. 24, p. 31-38, 1987/88).

* Educação e tecnologia. (a. 5, n. 5, p. 201-216, dez. 1957).

* Eficácia da sentença e coisa julgada perante terceiros. (a. 25 , n. 25 , p. 93-108, 1989).

- Eficácia probatória do comportamento das partes. (a. 20, n. 20, p. 1-10, 1981/82).

" Embargos de declaração. (a. 25, n. 25, p. 59-80. 1989). 
- Embargos de terceiro à penhcra: a questão da posse do promitente comprador. (a. 24, n. 24, p.17-30, 1987/88).

* A embriaguêz da vítima na etiologia do delito. (a. 5, n. 5, p. 54-58, dez. 1957).

* Embriaguêz no direito penal. (a. 4, n. 4, p. 257-284, dez. 1956).

* Em que sentido o direito natural é natural. (a. 2, n. 2, p. 158-173, dez. 1954).

* Encargos do ministério público no ramo civil. (a. 2, n. 2, p. 291-302, dez. 1954).

* Enquanto se espera pelas diretrizes e bases. (a. 1, n. 1, p. 73-90, dez. 1953).

* O ensino jurídico no Brasil. (a. 1, n. 1, p. 48-63, dez. 1953).

* Ensino profissional de economia. (a. 3, n. 3, p. 297-303, dez, 1955).

* A eqüidade e o direito do trabalho. (a. 19, n. 19, p. 17-39, 1978/79/80).

* Erro de fato e erro de direito no anteprojeto de código penal. (a. 9, n. 9. p. 33-52, 1961/63).

* O erro em matéria penal. (a. 5, n. 5, p. 35-53, dez. 1957).

* O erro no casamento. (a. 2, n. 2, p. 394-405, dez. 1954).

* Espécies de dolo e outros elementos subjetivos do tipo. (a. 14, n. 14, p. 107-120, 1971).

- O estado de direito e o direito de ação (a extensão do seu exercício). (a. 19, n. 19, p. 243-262, 1978/79/80).

* O estado de direito e os direitos da personalidade. (a. 19, n. $19,223-242,1978 / 79 / 80$ ).

* Estado de direito e segurança nacional. (a. 19, n. 19, p. 161-184, 1978/79/80).

* Estado de direito e segurança nacional. (a. 19, n. 19, p. 295-336, 1978/79/80).

* Estado de necessidade e a exigibilidade de outra conduta. (a. 15, n. 15, p. 185-207, 1972). 
* O estado singular e o direito plural. (a. 25 , n. 25 , p. 139-164, 1989).

* O estudo do direito no Brasil e no Paraná. (a. 1, n. 1, p. p. 157-169, dez. 1953).

* Estudo sobre o casamento com separação de bens no direito comparado. (a. 8, n. 8, p. 172-188, 1960).

* Estudos de direito tributário. (a. 16, n. 16, p. 63-140, 1973).

* Evolução da teoria da "universitas". (a. 2, n. 2, p. 44-68, dez. 1954).

* O excesso de adaptação das cartas estaduais à constituição de 1967. (a. 12, n. 12, p. 151-173, 1969).

* A extinção das ações ao portador. (a. 6/7, n. 6/7, p. 9-19, 1958/59).

* Fatores de desenvolvimento. (a. 10, n. 10, p. 107-130, 1964/67).

* Fatores geográficos e cultura de grau supeiror. (a. 4, n. 4, p. 143-156, dez. 1956).

* A ficção no direito. (a 11, n. 11, p. 145-160, 1968).

* Filosofia do direito como problema filosófico. (a. 17, n. 17, p. 9-20, 1974/75).

* Formação e aperfeiçoamento de juízes. (a. 8, n. 8, p. 114-123, 1960).

* A função renovadora do direito. (a. 12, n. 12, p. 39-48, 1969).

* A função social da empresa no estado de direito. (a. 19, n. 19, p. $263-280,1978 / 79 / 80)$.

* A função social da propriedade. (a. 25 , n. 25 , p. 165-182, 1989).

* Funcionamento da ONU. (a. 13, n. 13, p. 33-46, 1970).

* A fundação como forma de empresa. (a. 15, n. 15, p. 43-73, 1972).

* Fundamentos da geografia jurídica. (a. 2, n. 2, p. 174-262, dez. 1954). 
* Garantias jurídicas que protegem a propriedade nas desapropriações. (a. 20, n. 20, p. 39-50, 1981/82).

* Garantias jurisdicionais dos administrados em direito comparado. (a. 18. n. 18, p. 5-22, 1976/77).

* A generalidade da lei. (a. 8, n. 8, p. 22-43, 1960).

* O hipnotismo e a legislação penal brasileira. (a. 5, n. 5, p. 9-26, dez. 1957).

* Homologacion de sentencia extranjera. (a. 9, n. 9, p. 19-28, 1961/63).

* llícito penal e sanção disciplinar. (a. 10, n. 10, p. 51-60, 1964/67).

" O "impeachment" dos executivos nomeados no direito constitucional brasileiro. (a. 17, n. 17, p. 39-52. 1974/75).

* Impeachment e impedimento do titular do poder executivo. (a. 16, n. 16, p. 141-150, 1973).

* A importância da enciclopédia jurídica na formação do jurista. (a. 8, n. 8, p. 135-146, 1960).

* Impunidade das infrações a regras de aviação cometidas em alto mar. (a. 10, n. 10, p. 61-74, 1964/67).

* A imputabilidade e o princípio psiquiátrico-psicológico-jurídico. (a. 10, n. 10, p. 11-22, 1964/67).

* Imunidades parlamentares. (a. 22, n. 22, p. 166-179, 1985). 1960).

* Industrialismo em escala econômica. (a. 8, n. 8, p. 128-134,

* A informação cultural no estado de direito. (a. 19, n. 19, p. 185-212, 1978/79/80).

* A instituição do mandato nas sociedades limitadas. (a. 1, n. 1, p. 178-186, dez. 1953).

* Instituto de direito comparado na Universidade Federal do Paraná. (a. 6/7, n. 6/7, p. 85-100, 1958/59).

* Interpretação da lei penal. (a. 17, n. 17, p. 135-144, 1974/75).

* Interpretação das normas constitucionais. (a. 22, n. 22, p. 158-165, 1985). 
* Interpretação econômica da instabilidade política nacional. (a. 2, n. 2, p. 271-286, dez. 1954).

* Joaquim Nabuco. (a. 2, n. 2, p. 76-92, dez. 1954).

* Julgamento conforme o estado do processo (temas polêmicos). (a. 21, n. 21, p. 75-90, 1983/84).

* Jus novum. (a. 6/7, n. 6/7, p. 126-143, 1958/59).

* A legislação fóssil do Brasil e a menoridade social dos selvagens. (a. 4, n. 4, p. 20-34, dez. 1956).

" Legitimação per subsequens matrimonium. (a. 3, n. 3, p. 277-296, dez. 1955).

* Lei reguladora do estatuto pessoal. (a. 2, n. 2, p. 19-43, dez. 1954).

* Liberdades fundamentais da pessoa humana em face do Estado. (a. 3, n. 3, p. 172-252, dez. 1955).

* Liquidação de condomínio. (a. 15. n. 15, p. 162-165, 1972).

- O mandado de segurança como instrumento de liberdade civil e de liberdade poítica. (a. 19, n. 19, p. 5-16, 1978/ $79 / 80$ ).

" Mandados e sentenças liminares. (a. 14, n. 14, p. 7-28, 1971).

* Os mandamentos. (a. 20, n. 20. p. 11-18, 1981/82).

* Meios de invalidar o ato administrativo no Brasil. (a. 23, n. 23 , p. $37-50,1986)$.

* Métodos e processos de interpretação constitucional. (a. 22, n. 22, p. 146-157, 1985).

* As migrações do direito. (a. 4, n. 4, p. 307-323, dez. 1956).

* As migrações do direito romano. (a. 5, n. 5, p. 244-282, dez. 1957).

* Modas e práticas legais na execução dos serviços públicos. (a. 17, n. 17. p. 21-38, 1974/75).

* Momentos da conduta. (a. 10, n. 10, p. 131-138, 1964/67).

* A motivação da sentença como garantia inerente ao estado de direito. (a. 19, n. 19, p. 281-294, 1978/79/80). 
* A mulher e o crime. (a.3, n.3, p. 132-145, dez. 1955).

- O Município na evolução constitucional do Brasil. (a. 18, n. 18, p. 43-50, 1976/77).

- Negócio fiduciário, negócio indireto e negócio simulado uma tentativa de distinção. (a. 15, n. 15, p. 248-260, 1972).

* O notário e o mundo de hoje. (a. 13, n. 13, p. 47-88, 1970).

* Notas sobre a ação revocatória. (a. 13, n. 13, p. 207-220, 1970).

* Notícia sobre a parte geral do novo código civil português. (a. 12, n. 12, p. 55-92, 1969).

- La notificación automática en la Província de Santa Fé. (a. 21 , n. 21, p. 129-140, 1983/84).

- Nova conceituação do recurso extraordinário na constituição do Brasil. (a. 11, n. 11, p. 51-66, 1968).

- O novo currículo mínimo de direito e o direito internacional. (a. 15, n. 15, p. 7-14, 1972).

- Novos rumos à didática dos cursos jurídicos. (a. 4, n. 4, p. 285-297, dez. 1956).

* La nueva empresa. (a. 11, n. 11, p. 19-50, 1968).

* Nulidade da alienação fiduciária quando o empréstimo não se destina à aquisição do bem dado em garantia. (a. 25, n. 25 , p. $119-124,1989$ ).

- Origens da limitação legal na jornada de trabalho. (a. 22, n. 22, p. 250-261, 1985).

* As origens luso-brasileiras do mandado de segurança. (a. 21, n. 21, p. 1-12, 1983/84).

" Papel da má literatura dos "comics" norte-americanos sobre o psiquismo das crianças e dos adolescentes. (a. 9, n. 9, p. 73-84, 1961/63).

* A parte geral do anteprojeto do código civil brasileiro. (a. 15 , n. 15, p. 137-161, 1972).

* Pena privada de liberdade. (a. 13, n. 13, p. 167-206, 1970). 
- A periculosidade criminal. (a. 4, n. 4, p. 63-82, dez. 1956).

* La persona umana di fronte al diritto. (a. 3, n. 3, p. 253-276, dez. 1955).

* Personalidade jurídica da sociedade irregular. (a. 10, n. 10, p. 139-162, 1964/67).

* Pessoas internacionais. (a. 6/7, n. 6/7, p. 238-267, 1958/59).

* Poder da binuba sobre os filhos do leito anterior. (a. 4, n. 4, p. 131-142, dez. 1956).

- Política fiscal em países subdesenvolvidos. (a. 3, n. 3, p. 21-99, dez. 1955).

* A positividade como expressão do direito. (a. 4, n. 4, p. 105-109, dez. 1956).

* A posse no código civil brasileiro. (a. 10, n. 10, p. 43-50, 1964/67).

* A possibilidade da unificação do direito privado hispanoluso-americano. (a. 2, n. 2, p. 9-18, dez. 1954).

* O princípio da responsabilidade do Estado - evolução e fundamentos. (a. 23 , n. 23, p. 73-88, 1986).

* Os princípios gerais do direito civil. (a. 22, n. 22, p. 272-285, 1985).

* Princípios gerais do processo penal. (a. 22, n. 22, p. 210-219, 1985).

" Prisão civil e "equivalente em dinheiro" no depósito acessório. (a. 25, n. 25, p. 189-206, 1989).

* O problema da causa nas obrigações contratuais. (a. 6/7, n. $6 / 7$, p. $71-84,1958 / 59)$.

* O problema da definição do direito. (a. 2, n. 2, p. 136-147, dez. 1954).

* O problema da paz e o subdesenvolvimento econômico. (a. 8, n. 8, p. 44-54, 1960).

- O problema da soberania e o direito das gentes. (a. 1, n. 1, p. 170-177, dez. 1953). 
* Problemas atuais da execução penal. (a. 20, n. 20, p. 51-70, 1981/82).

* Problemas modernos de educação. (a. 3, n. 3, p. 313-321, dez. 1955).

* Procedimento cumaríssimo: necessidade de sua reformulação. (a. 21, n. 21, p. 91-100, 1983/84).

* Processo de execução - alguns temas polêmicos. (a. 19, n. 19 , p. $127-146,1978 / 79 / 80$ ).

* Processo e direito administraćivo. (a. 2, n. 2, p. 122-135, 1954).

* Processo penale: legalitá, giustizia e difesa sociale. (a. 11 , n. 11, 7-18, 1968).

* A realidade multinacional e as implicações da nacionalidade no direito internacional privado. (a. 25 , n. 25, p. 1-58, 1989).

* A recuperação social dos delinqüentes. (a. 5, n. 5, p. 68-85, dez. 1957).

* Recurso ordinário: a amplitude do efeito devolutivo e o duplo grau de jurisdição. (a. 24, n. 24, p. 75-104. 1987/88).

* A redivisão territorial do Brasil e o poder constituinte. (a. 12, n. 12, p. 221-240, 1969).

* Redução do capital de sociedade anônima. (a. 11, n. 11, p. 81-114, 1968).

* Reflexões sobre direito e processo. (a. 14, n. 14, p. 45-72, 1971).

* Reforma da lei das scciedades por ações. (a. 13, n. 13, p. 105-138, 1970).

* Reforma do sistema bancário. (a. 5, n. 5, p. 121-152, dez. 1957).

* O registro civil da pessoa natural no direito brasileiro. (a. 5, n. 5, p. 59-67, dez. 1957).

* Relações financeiras da União com as outras órbitas de governo. (a. 1, n. 1, p. 5-25, dez. 1953). 
- Relatório sobre o anteprojeto da parte especial do código penal. (a. 22, n. 22, p. 180-185, 1985).

* Remédios processuais da administração e contra administração. (a. 8, n. 8, p. 100-113, 1960).

* Repressão internacional da criminalidade. (a. 1, n. 1, p. 121-146, dez. 1953).

* O repúdio das mulheres pelo marido no direito muçulmano, visto pelo Supremo Tribunal Federal. (a. 20, n. 20, p. 133-160, 1981/82).

- Responsabilidade civil do Estado e denunciação da lide. (a. 23 , n. 23 , p. $129-206,1986$ ).

* Responsabilidade civil do Estado pela intervenção no domínio econômico-material para discussão do tema. (a. 23, n. 23, p. 269-282, 1986).

* Responsabilidade do Estado por atividade lícita: especialidade e anormalidade do dano. (a. 23, n. 23, p. 207-226, 1986).

* Responsabilidade patrimonial do Estado. O Estado. Os sujeitos que o compõem. Vítimas do dano. 0 usuário e o terceiro. (a. 23, n. 23, p. 89-104, 1986).

- A responsabilidade patrimonial do Estado por atos criminosos de terceiros. (a. 23, n. 23. p. 227-246, 1986).

* Responsabilidade sem culpa. (a. 4, n. 4, p. 234-250, dez. 1956).

* Restrições e concessões aos direitos dos estrangeiros. (a. 4, n. 4, p. 35-62, dez. 1956).

- Reumatismo, doença do trabalho. (a. 5, n. 5, p. 109-120, dez. 1957).

- Revisão do crime continuado. (a. 12, n. 12, p. 173-190, 1969).

* O Senador Correia. (a. 6/7, n. 6/7, p. 20-57, 1958/59).

* Sentenças estrangeiras do divórcio. (a. 5, n. 5, p. 223-243, dez. 1957).

- Sentenças estrangeiras meramente declaratórias do estado das pessoas. (a. 9, n. 9, p. 29-32, 1961/63). 
* Síntese analítica da conjuntura econômica do Paraná e do Brasil em 1958. (a. 6/7, n. 6/7, p. 63-70, 1958/59).

* Sistemas determinadores da nacionalidade da pessoa jurídica e o direito internacional privado brasileiro. (a. 12, n. 12 , p. 241-256, 1969).

* Sistemas y experiencias en enseñanza practica o aplicados para las profesiones jurídicas. (a. 10, n. 10, p. 75-88, 1964/67).

* Sobre a problemática: -certeza no direito. (a. $6 / 7$, n. 6/7, p. 221-227, 1958/59).

* Sobre as doutrinas do reconhecimento. (a. 4, n. 4, p. 9-19, dez. 1956).

* Sobre direito e ideologia. (a. 22, n. 22. p. 262-271, 1985).

* Sobre o anteprojeto de novo código penal. (a. 9, n. 9, p. 57-62, 1961/63).

* Sociedade e Estado. (a. 6/7, n. 6/7, p. 179-187, 1958/59).

* As sociedades arônimas de capital autorizado e de capital aberto. (a. 11, n. 11, p. 133-144, 1968).

* Sugestões ao anteprojeto do código civil. (a. 15, n. 15, p. $74-129,1972$ ).

* Televisão - problema médico-social de relevo. (a. 11, n. 11. p. 115-132, 1968).

* Temas do processo civil. (a. 4, n. 4, p. 157-169, dez. 1956).

* A teoria da norma jurídica de N. Bobbio e o direito penal brasileiro. (a. 22, n. 22, p. 220-223, 1985).

* Teoria do Estado Composto. (a. 1, n. 1, p. 187-228, dez. 1953).

* Teorias atuais da pena e o projeto de reforma penal brasileiro. (a. 22, n. 22, p. 186-201, 1985).

* Tipo formal. (a. 24, n. 24, p. 1-16, 1987/88).

* Títulos hábeis para o pedido de falência. al. 3, n. 3, p. 322-336, dez. 1955). 
* Transformação do direito. (a. 3, n. 3, p. 337-347, dez. 1955).

* Tratamento jurídico da retrocessão. (a. 12, n. 12, p. 191-202, 1969).

* As tropas da ONU e seu estatuto jurídico. (a. 1. n. 1, p. 98-120, dez. 1953).

* A Tutela dos bens culturais e a responsabilidade patrimonial do Estado. (a 23, n. 23, p. 247-268, 1986).

* Tutela dos direitos no código civil português. (a. 12, n. 12 , p. 115-136, 1969).

* Tutela sancionatória e tutela preventiva. (a. 19, n. 19, p. 117-126, 1978/79/80).

* Um novo caso de qualificativa penal em homicídio. (a. 2. ri. 2, p. 69-75, dez. 1954).

* Uma visão sistemático-dogmática da pena. (a. 19, n. 19, p. 147-160, 1978/79/80).

* Unidade educacional. (a. 3, n. 3, p. 9-20, dez. 1955).

* La universidad latinoamericana y la eclosion pedagógica. (a. 15, n. 15, p. 15-19, 1972).

* Vagas não preenchidas em escolas superiores. (a. 4, n. 4, p. 251-256, dez. 1956).

* Velhice e casamento. (a. 5, n. 5, p. 166-192, dez. 1957).

* Velhice e suicídio. (a. 4, n. 4, p. 83-104, dez. 1956).

* A vigilância privada: auxiliar do sistema de proteção e defesa social. (a. 24, n. 24, p. 193-204, 1987/88). 